\title{
Comparison of Electron Beam and Laser Beam Powder Bed Fusion Additive Manufacturing Process for High Temperature Turbine Component Materials
}

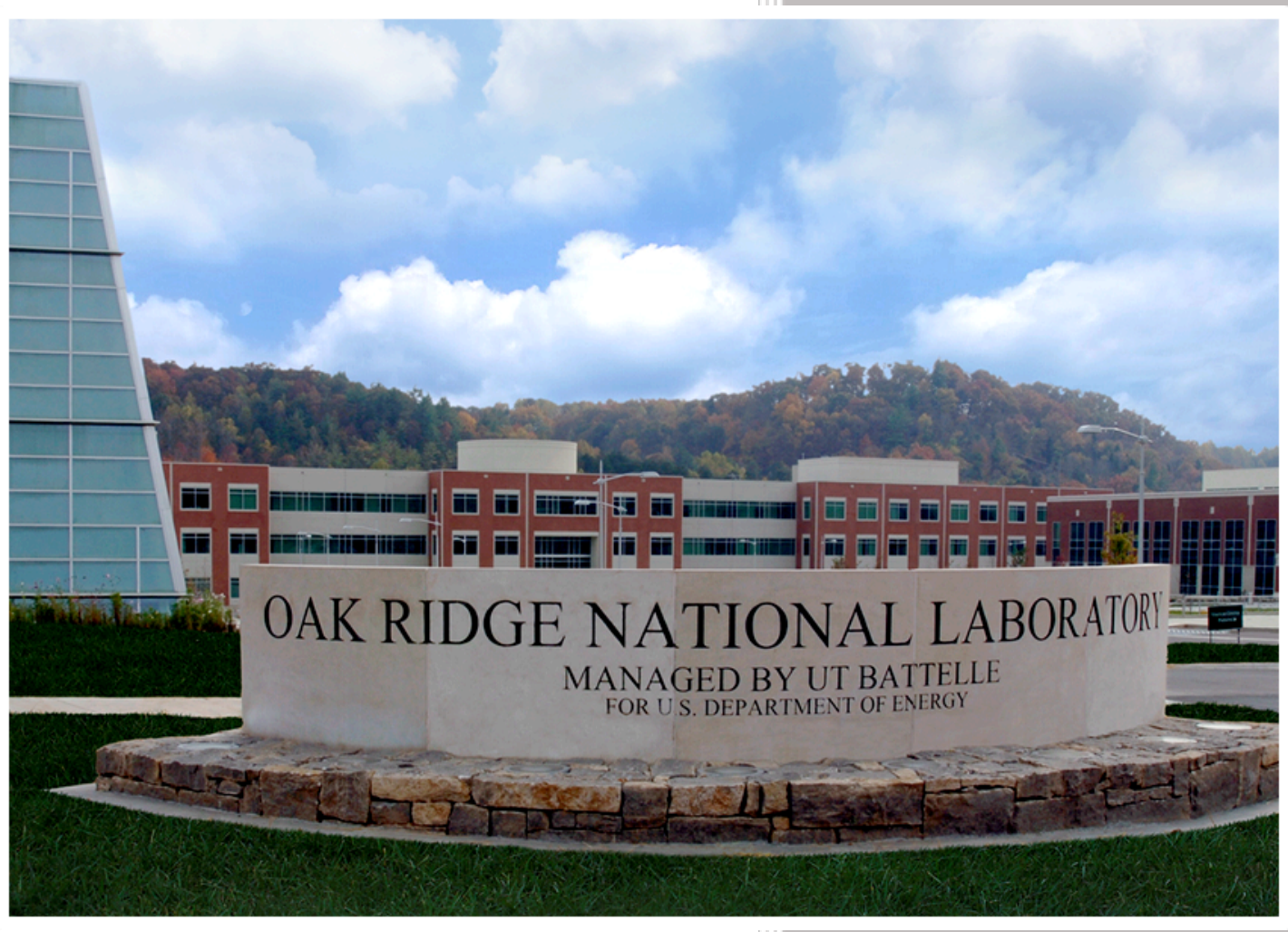

\section{CRADA FINAL REPORT NFE-15-05495}

Approved for Public Release. Distribution is Unlimited.
Sebastien Dryepondt

April 22, 2016 


\title{
DOCUMENT AVAILABILITY
}

Reports produced after January 1, 1996, are generally available free via US Department of Energy (DOE) SciTech Connect.

Website http://www.osti.gov/scitech/

Reports produced before January 1, 1996, may be purchased by members of the public from the following source:

\author{
National Technical Information Service \\ 5285 Port Royal Road \\ Springfield, VA 22161 \\ Telephone 703-605-6000 (1-800-553-6847) \\ TDD 703-487-4639 \\ Fax 703-605-6900 \\ E-mail info@ntis.gov \\ Website http://www.ntis.gov/help/ordermethods.aspx
}

Reports are available to DOE employees, DOE contractors, Energy Technology Data Exchange representatives, and International Nuclear Information System representatives from the following source:

Office of Scientific and Technical Information

PO Box 62

Oak Ridge, TN 37831

Telephone 865-576-8401

Fax 865-576-5728

E-mail reports@osti.gov

Website http://www.osti.gov/contact.html

This report was prepared as an account of work sponsored by an agency of the United States Government. Neither the United States Government nor any agency thereof, nor any of their employees, makes any warranty, express or implied, or assumes any legal liability or responsibility for the accuracy, completeness, or usefulness of any information, apparatus, product, or process disclosed, or represents that its use would not infringe privately owned rights. Reference herein to any specific commercial product, process, or service by trade name, trademark, manufacturer, or otherwise, does not necessarily constitute or imply its endorsement, recommendation, or favoring by the United States Government or any agency thereof. The views and opinions of authors expressed herein do not necessarily state or reflect those of the United States Government or any agency thereof. 
ORNL/TM-2016/47

CRADA/NFE- 15-05495

Materials Science and Technology Division
Advanced Manufacturing Office

\title{
Comparison of Electron Beam and Laser Beam Powder Bed Fusion Additive
} Manufacturing Process for High Temperature Turbine Component Materials

\author{
Authors \\ Sebastien Dryepondt \\ Michael Kirka \\ Bruce A. Pint \\ Daniel Ryan
}

Date Published:

April 22, 2016

Prepared by

OAK RIDGE NATIONAL LABORATORY

Oak Ridge, Tennessee 37831-6283

managed by

UT-BATTELLE, LLC

for the

US DEPARTMENT OF ENERGY

under contract DE-AC05-00OR22725

Approved For Public Release 



\section{CONTENTS}

Page

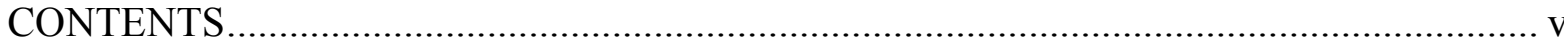

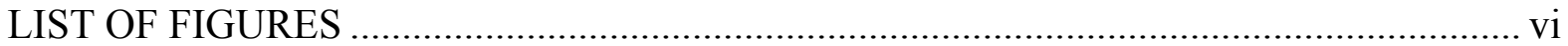

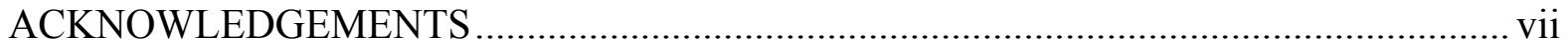

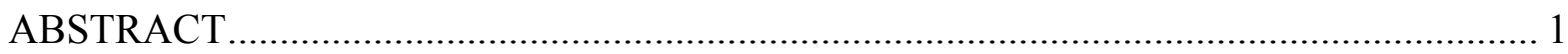

1. Comparison of Electron Beam and Laser Beam Powder Bed Fusion Additive Manufacturing Process for High Temperature Turbine Component Materials ...................... 1

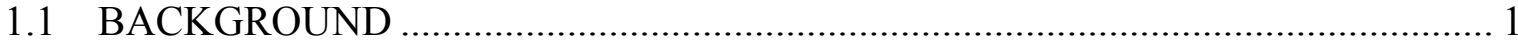

1.2 TECHNICAL RESULTS............................................................................. 2

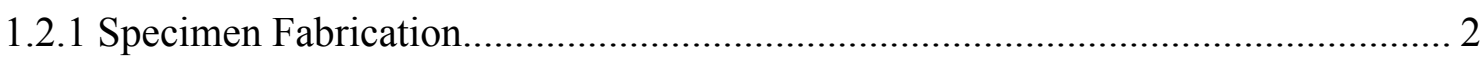

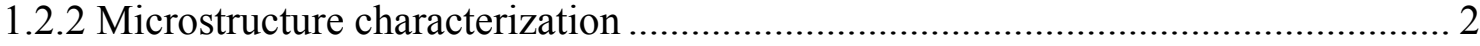

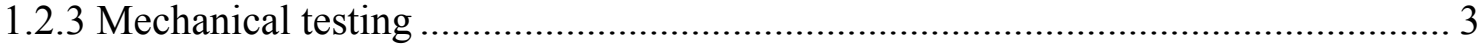

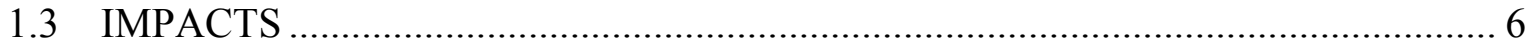

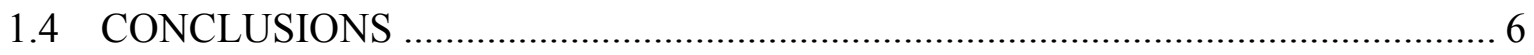

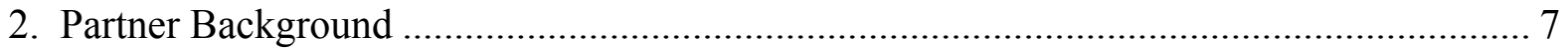




\section{LIST OF FIGURES}

Fig. 1. Build configuration for a) LB-PBF test bars and b) 10 of EB-PBF test bars ............. 2 Fig. 2. Scanning electron micrographs showing the microstructure of the LB-PBF rods after annealing for $15 \mathrm{~min}$ at $2150^{\circ} \mathrm{F}$ and the as fabricated EB-PBF rods, a) LB-PBF rod along the build direction, b) LB-PBF rod perpendicular to the build direction, c) EB-PBF rod along the build direction and d) \& e) EB-PBF rod perpendicular to the build direction. 3 Fig. 3. Tensile properties for Nickel Alloy X LB-PBF and EB-PDF specimens, a) Yield strength, b) Ultimate tensile strength and c) Total elongation. Haynes's data for wrought Nickel Alloy X and the minimum requirement for cast Nickel Alloy X were added for comparison.

Fig. 4. Low cycle fatigue behavior of EB-PBF and LB-PBF specimens at $800^{\circ} \mathrm{F}$. Data for wrought Nickel Alloy X were added for comparison 


\section{ACKNOWLEDGEMENTS}

This CRADA NFE-15-05495 was conducted as a Technical Collaboration project within the Oak Ridge National Laboratory (ORNL) Manufacturing Demonstration Facility (MDF) sponsored by the US Department of Energy Advanced Manufacturing Office (CPS Agreement Number 24761).

Opportunities for MDF technical collaborations are listed in the announcement "Manufacturing Demonstration Facility Technology Collaborations for US Manufacturers in Advanced

Manufacturing and Materials Technologies" posted at http://web.ornl.gov/sci/manufacturing/docs/FBO-ORNL-MDF-2013-2.pdf. The goal of technical collaborations is to engage industry partners to participate in short-term, collaborative projects within the Manufacturing Demonstration Facility (MDF) to assess applicability and of new energy efficient manufacturing technologies. Research sponsored by the U.S. Department of Energy, Office of Energy Efficiency and Renewable Energy, Advanced Manufacturing Office, under contract DE-AC0500OR22725 with UT-Battelle, LLC.

The authors would like to thank L. Lowe, G. S. Marlow, S. Jones, T. Jordan, C. Stevens and J. Moser for their help with experimental work. 



\begin{abstract}
3D printing has routinely been used by industry for development prototyping activities, however the evolving technology is now at the point where production additive manufacturing applications are emerging. However, for additive manufacturing to find widespread adoption, significant activity is needed to qualify the AM processes and components to meet current design and quality standards. The goal of the project was to begin characterization of the microstructure and mechanical properties of Nickel Alloy X (Ni-22Cr-18Fe-9Mo) test bars fabricated by powder bed fusion (PBF) AM processes that use either an electron beam (EB) or laser beam (LB) power source. This investigation revealed the AM materials produced with the EB and LB processes displayed significant differences in microstructure and resultant mechanical properties. Accordingly, during the design analysis of AM turbine components, the specific mechanical behavior of the material produced with the selected AM process should be considered. While additional characterization of the AM processes is still needed, preliminary comparison of the mechanical properties of both the EB and LB materials to those of conventionally processed Nickel Alloy X materials indicates the subject AM materials are viable alternatives for manufacture of some turbine components.
\end{abstract}

\title{
1. COMPARISON OF ELECTRON BEAM AND LASER BEAM POWDER BED FUSION ADDITIVE MANUFACTURING PROCESS FOR HIGH TEMPERATURE TURBINE COMPONENT MATERIALS
}

This phase 1 technical collaboration project (MDF-TC-2014-056) was begun on February 2, 2015 and was completed on January 21, 2015. The collaboration partner Solar Turbines Incorporated is a large business. The mechanical properties of Nickel Alloy X specimens fabricated by EB-PBF and LB-PBF processes met the specification requirements for cast Nickel Alloy X.

\subsection{BACKGROUND}

The primary markets for Solar Turbines are Industrial Power Generation and Oil and Gas, and Solar Turbines has been evaluating metal 3D printing AM for the development and production of industrial gas turbine components. Some of these components have historically been investment cast and machined, a process that is expensive and time consuming. In addition, many of these components are subject to very high temperatures and stresses during operation so high performance alloys are used, which can be difficult to cast and machine. These components may also have complex geometries that make it challenging to cast and meet the design and dimensional requirements.

There are several 3D printing AM technologies available today and Solar Turbines has evaluated multiple AM processes by fabricating development components using Nickel Alloy X powder. The quality of the components is promising, but occurrences of porosity, micro-cracking, voids, and lack of fusion remain a concern.

Solar Turbines would like to gain a better understanding of the potential benefits of other additive manufacturing processes such as EB-PBF (Arcam). The goal of this project is therefore to characterize the microstructure and mechanical properties of Nickel Alloy X test bars fabricated using EB-PBF (Arcam) process at ORNL and LB-PBF (3D Systems) process at Solar Turbines. These mechanical properties will be compared with the specification requirements for cast Nickel Alloy X (reference AMS5390). Nickel alloy $\mathrm{X}(\mathrm{Ni}-22 \mathrm{Cr}-18 \mathrm{Fe}-9 \mathrm{Mo})$ has wide use in hot sections of gas turbine engines and was originally developed by Haynes International under the name Hastelloy X.[1] 


\subsection{TECHNICAL RESULTS}

\subsubsection{Specimen Fabrication}

Twenty-nine (29) Nickel Alloy X test bars, 3.5" long (build direction) and 0.5" in diameter, were fabricated by Solar Turbines using a LB-PBF 3D Systems machine. To homogenize the microstructure, the test bars were then annealed at $2150^{\circ} \mathrm{F}\left(1177^{\circ} \mathrm{C}\right)$ for 15 minutes and cooled to room temperature using a gas fan. Test specimens were finally machined to conduct 17 tensile tests, 3 creep tests and 8 low cycle fatigue tests.

Seven (7) runs were performed at ORNL using an EB-PBF Arcam system to optimize the build parameters and fabricate two sets of ten (10) Nickel Alloy X rods similar to the test bars produced by Solar Turbines. Specimens were machined from the as-fabricated test bars.

Test bar configuration for the LB-PBF and EB-PBF systems are shown in Fig. 1.
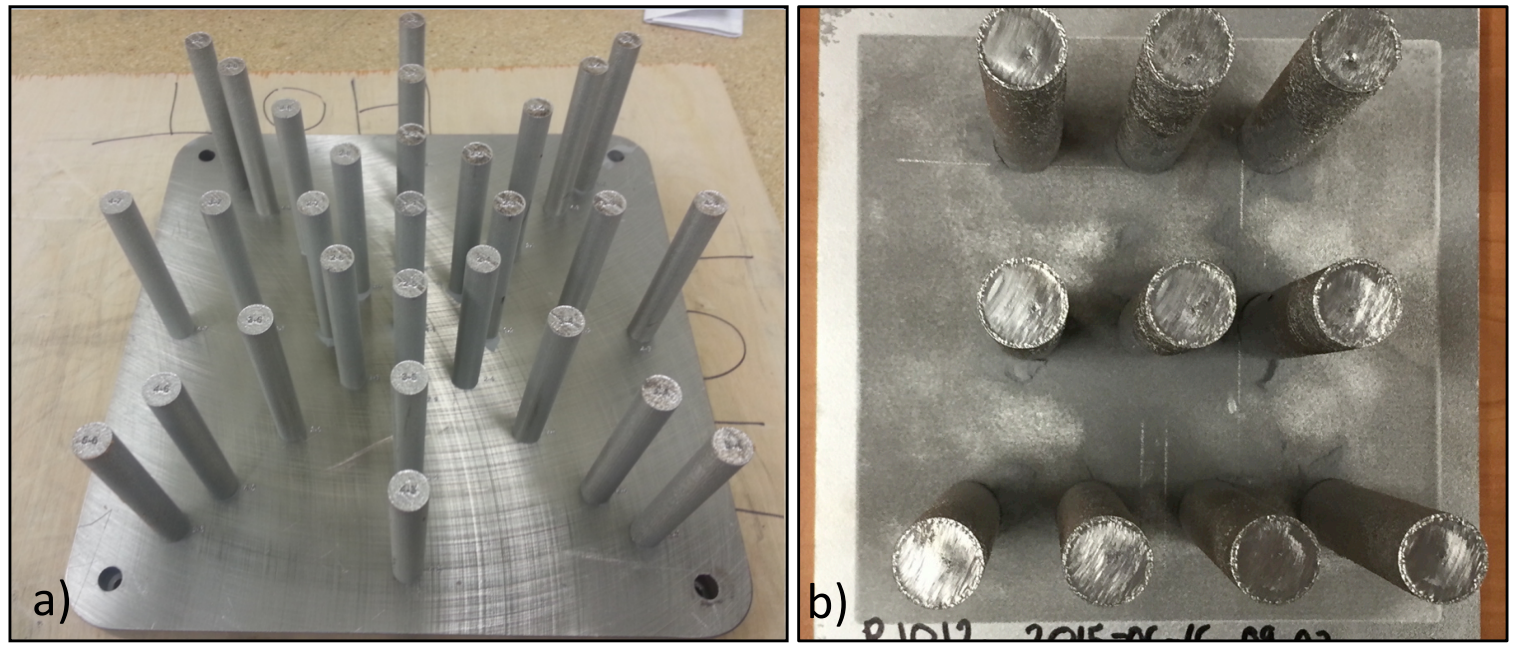

Fig. 1. Build configuration for a) LB-PBF test bars and b) 10 of EB-PBF test bars

\subsubsection{Microstructure characterization}

The microstructure of the annealed LB-PBF and as fabricated EB-PBF rods are shown in Fig. 2. The grain microstructures were elongated along the build $(Z)$ direction, particularly for the EB-PBF material, and bimodal grain size distributions were observed. Large precipitates were observed along the grain boundaries for both rod types, and energy dispersive X-ray spectroscopy (EDS) revealed that these grain boundary precipitates are very rich in molybdenum and silicon. X-ray measurements identified them as either $\mathrm{MC}_{6}$ or $\mathrm{M}_{23} \mathrm{C}_{6}$ carbides. It is also worth noting that some grain boundaries in the EB-PBF material appeared to be precipitate-free (white arrows in Fig. $2 \mathrm{c}$ and 2d.).

As can be seen in Fig 2a and 2b, a high density of sub-micron precipitates was observed in the center of the LB-PBF grains, with depleted zones close to the grain boundaries. For the EB-PBF alloy (Fig. $2 \mathrm{c}$ to $2 \mathrm{e}$ ), isolated precipitates, $\sim 1 \mu \mathrm{m}$ to $10 \mu \mathrm{m}$ in size were found, as well as very fine precipitates. Transmission electron microscopy will be required to characterize these fine precipitates. Finally, porosity in the powder used to fabricate the EB-PBF rods led to the presence of small voids in the alloy more or less aligned along the build direction (see black arrows in Fig. 2e). 

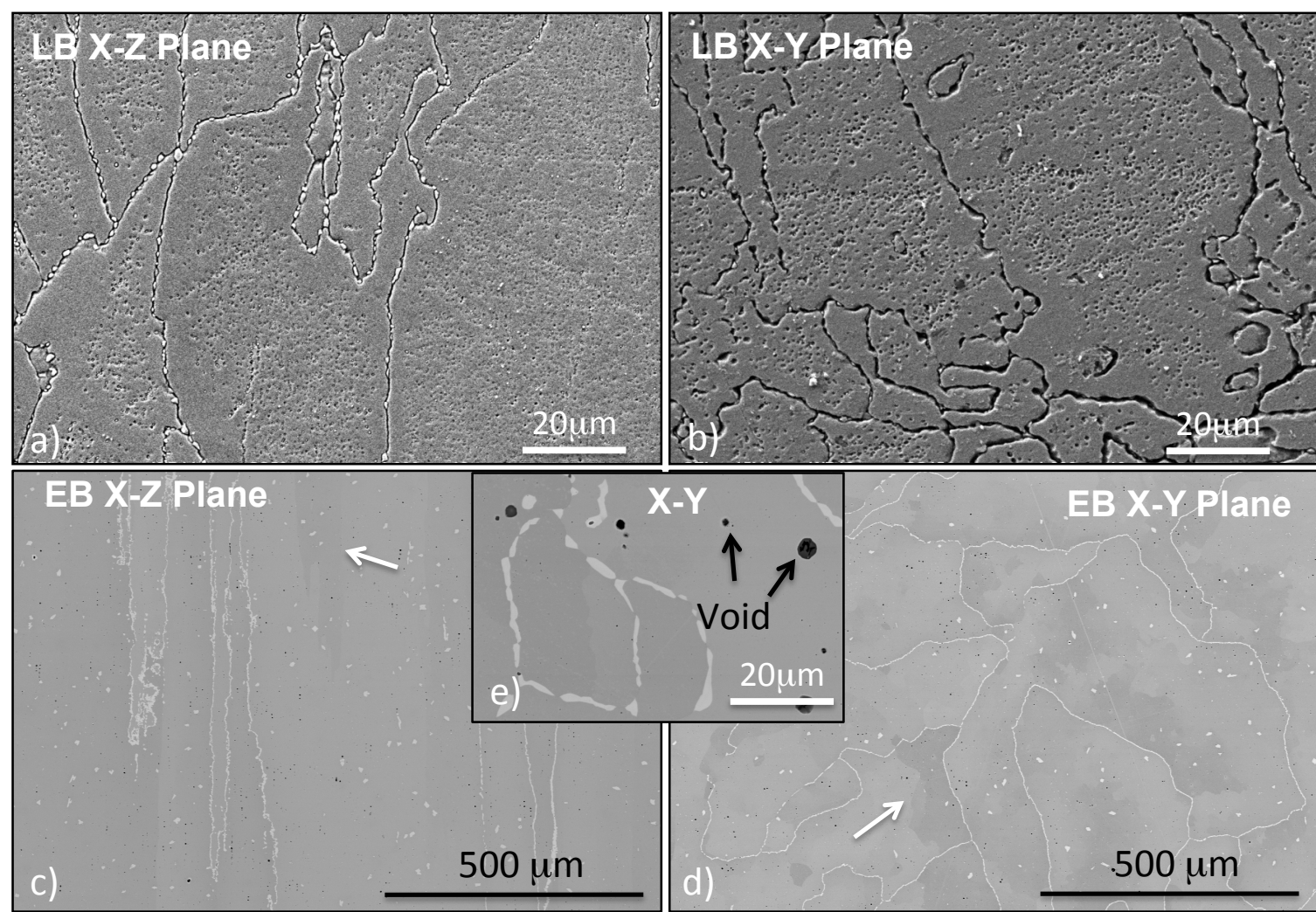

$\mathrm{X}-\mathrm{Y}$

EB X-Y.Plane

Fig. 2. Scanning electron micrographs showing the Nickel Alloy X microstructures of the LB-PBF rods after annealing for 15 minutes at $2150^{\circ} \mathrm{F}$ and the as fabricated EB-PBF rods, a) LB-PBF rod along the build direction, b) LB-PBF rod perpendicular to the build direction, c) EB-PBF rod along the build direction and d) \& e) EB-PBF rod perpendicular to the build direction.

\subsubsection{Mechanical testing}

Tensile testing of both the EB-PBF and LB-PBF specimens was performed from room temperature to $1650^{\circ} \mathrm{F}\left(899^{\circ} \mathrm{C}\right)$. The resulting tensile properties are compared in Fig. 3 with the tensile properties of wrought Nickel Alloy X (Haynes International datasheet [1]) and the minimum properties requirement for cast Nickel Alloy X based on reference AMS5390. 

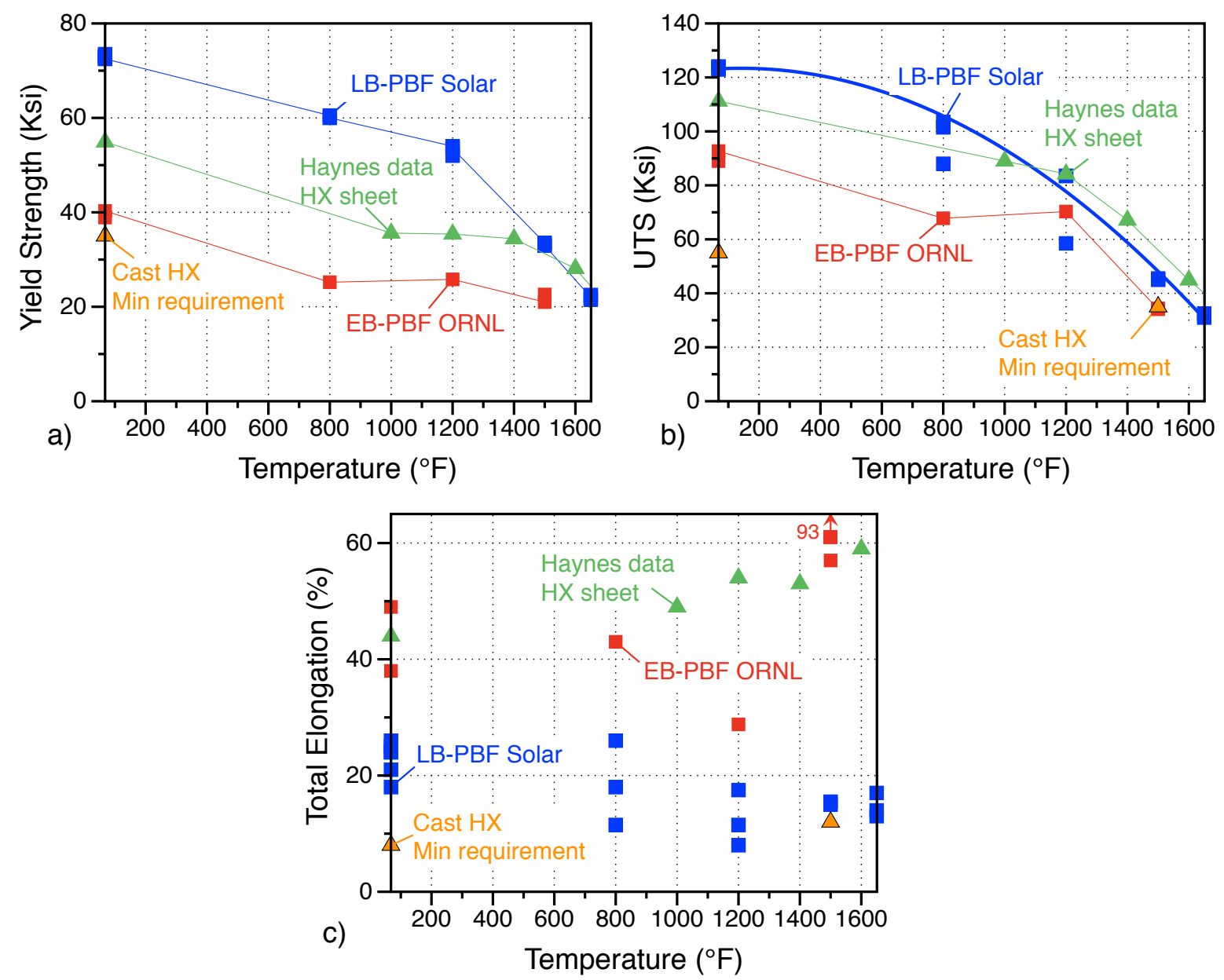

Fig. 3. Tensile properties for Nickel alloy X LB-PBF and EB-PDF specimens, a) $0.2 \%$ Yield strength, b) Ultimate tensile strength and c) Total elongation. Haynes International's data for wrought Nickel Alloy $X$ and the minimum requirement for cast Nickel Alloy $X$ were added for comparison

The $0.2 \%$ yield strength (YS) values for the LB-PBF alloy were significantly higher than the YS values for the wrought alloy below $\sim 1400^{\circ} \mathrm{F}$ (Fig. 3a). At higher temperature, the YS for LB-PBF and wrought materials were similar. The EB-PBF alloy exhibited lower YS values at all temperatures, but the YS at room temperature was still above the minimum requirement for cast Nickel Alloy X.

The ultimate tensile strength (UTS) values for the LB-PBF alloy were slightly higher at temperatures below $1000^{\circ} \mathrm{F}$ and slightly lower at temperature above $1000^{\circ} \mathrm{F}$ when compared to the UTS values for wrought Nickel Alloy X (Figure 3b). However, it should be noted that two EB-PBF specimens (one tested at $800^{\circ} \mathrm{F}$ and one tested at $1200^{\circ} \mathrm{F}$ ) failed at stresses lower than expected. The total percent elongations for these two tests were also very low at $11.5 \%$ and $8 \%$, respectively, which indicates that local defects might have been the cause of these specimens. The UTS results for the EB-PBF alloy were also lower than the LB-PBF values, but met the minimum requirement for cast Nickel Alloy X.

In contrast to the lower tensile strength displayed by the EB-PBF specimens, excellent ductility was evident by higher elongation properties (Fig. 3c). Except for the $1200^{\circ} \mathrm{F}$ test, the elongation was similar to the ductility of the wrought Nickel Alloy X. The LB-PBF material 
exhibited notably lower elongation, and the one specimen tested at $1200^{\circ} \mathrm{F}$ failed the minimum requirement for cast nickel alloy $\mathrm{X}$.

Creep tests were conducted at $1500^{\circ} \mathrm{F}\left(816^{\circ} \mathrm{C}\right)$ with an applied stress of $15 \mathrm{ksi}(103 \mathrm{MPa})$, and the time to rupture, deformation at rupture, and times to reach $1 \%$ deformation are given in Table 1 . These results are very consistent with the tensile data at $1500^{\circ} \mathrm{F}$ with longer times to rupture (130h to $182 \mathrm{~h}$ ) for the stronger LB-PBF specimens with very limited deformations at rupture. In contrast, the ductile EB-PBF specimens failed after only $\sim 40$ hour but displayed $\sim 90 \%$ reduction at rupture.

Table 1. Creep test results of Nickel Alloy X LB-PBF and EB-PBF specimens at $1500^{\circ} \mathrm{F}$ and 15 ksi

\begin{tabular}{|c|c|c|c|}
\hline Specimens & $\begin{array}{c}\text { Rupture time } \\
\text { (hours) }\end{array}$ & $\begin{array}{c}\text { Elongation } \\
(\%)\end{array}$ & $\begin{array}{c}\text { Time (hours) to reach } \\
1 \%\end{array}$ \\
\hline LB-PBF & 168 & 2.9 & 73.6 \\
\hline LB-PBF & 181.4 & 2.8 & 103.3 \\
\hline LB-PBF & 130.8 & 3.5 & 71.1 \\
\hline EB-PBF & 32.7 & 91.2 & 1.8 \\
\hline EB-PBF & 42.5 & 85.5 & 1.9 \\
\hline
\end{tabular}

Fully-reversed low cycle fatigue (LCF) tests were conducted at $800^{\circ} \mathrm{F}\left(427^{\circ} \mathrm{C}\right)$ with a total strain of $0.8 \%$ for the EB-PBF specimens and a total strain varying from $0.4 \%$ to $1 \%$ for the LBPBF specimens. The resulting cycles to failure are plotted in Fig. 4 with the published results for wrought Nickel alloy X.[2] The fatigue life of the LB-PBF specimens were slightly lower than the wrought Nickel Alloy X and the fatigue life of the EB-PBF specimens was significantly greater. The increased life was likely due to the greater ductility of the EB-PBF alloy.

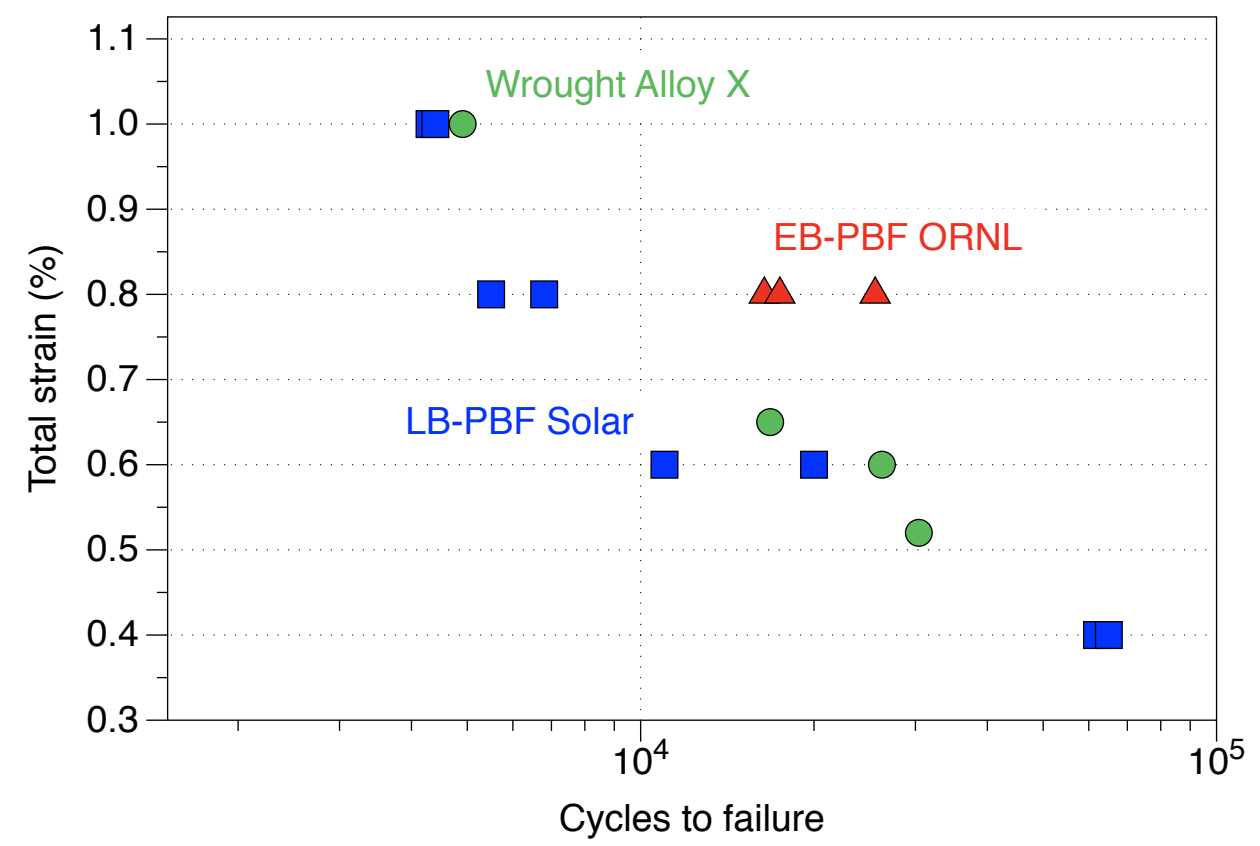

Fig. 4. Low cycle fatigue behavior of Nickel alloy $X$ EB-PBF and LB-PBF specimens at $800^{\circ} \mathrm{F}$. Data for wrought nickel alloy $X$ were added for comparison [2] 


\section{References}

[1] Haynes International's datasheet, Hastelloy X alloy, https://www.haynesintl.com/pdf/h3009.pdf

[2] C. R. Brinkman et al., "Application of Hastelloy X in Gas-Cooled Reactor Systems," ORNL/TM-5405, Oak Ridge National Laboratory (Oct. 1976).

\subsection{IMPACTS}

The differences in mechanical properties of the EB and LB materials will require generation of AM process specific material properties data curves to support turbine component design analysis activities. The EB and LB materials properties displayed substantial overlap with those of conventional cast and wrought forms of Nickel Alloy X materials currently used in gas turbine applications, indicative that the subject AM materials are viable alternatives for manufacture of some turbine components.

Use of AM processes to create metallic turbine components for development and production purposes promises to yield significant financial benefit and competitive advantage to industrial gas turbine manufacturers. Product development cycle times can be reduced and product quality improved due to the rapid design and manufacturing iterative capability that AM technology provides. Additionally, product costs can be reduced relative to conventional manufacturing processes for components with complex geometries.

\subsection{CONCLUSIONS}

Initial assessment of EB and LB produced AM Nickel Alloy X materials revealed significant differences in microstructure and mechanical behavior, and prior to application in production gas turbine engines, additional comprehensive testing is needed of the mechanical behavior of the materials produced with the EB and LB processes. Evaluation of AM process repeatability and development of manufacturing process controls are needed to ensure ongoing production of consistent material quality. Future detailed assessment of AM Nickel Alloy X material behavior and process repeatability should be tailored to meet the geometric and in-service performance requirements of high temperature turbine components. Additional evaluation of mechanical properties in multiple build orientations, high temperature oxidation, and corrosion behavior is recommended. Dimensional capability of the AM processes to produce geometric features typical of high temperature turbine components is needed. Development of in-process monitoring and non-destructive inspection techniques are needed to ensure ongoing quality of AM produced components. 


\section{PARTNER BACKGROUND}

Solar Turbines Incorporated, a wholly owned subsidiary of Caterpillar, headquartered in San Diego, California, employs approximately 8,000 employees, most of which are located at the headquarters in San Diego, California. Solar Turbines is a leading industrial gas turbine original equipment manufacturer (OEM), offering a range of gas turbines and turbomachinery equipment in the 1-22 MW range for oil \& gas exploration and transmission, and for power generation and cogeneration. Solar Turbines' state-ofthe-art gas turbines are complemented by a line of compressors that can be matched with Solar Turbines equipment, or that of other OEMs. More than 13,370 Solar Turbines units, operating in 90 countries, account for over 1.4 billion hours of operating experience.

Solar Turbines has over 50 years of experience with the design, development and commercialization of industrial gas turbines and turbomachinery products. Solar Turbines has a long record of development of gas turbine technologies from internally funded and government programs. An example of a successful government-industry partnership was the DOE-Solar Advanced Turbine Systems (ATS) program, which resulted in the development of the 4.6 MWe Mercury 50 recuperated gas turbine. Solar Turbines has also been involved in the development of gas turbine products for renewable energy including bio-gas and solar energy. 